\title{
A PROSPECTIVE STUDY OF THE CLINICAL PROFILE OF PATIENTS PRESENTING WITH ANTERIOR UVEITIS
}

\author{
Shaik Mohammed Pervaiz Hussain'1, Afia Mirza² \\ ${ }_{1}^{1}$ Assistant Professor, Department of Ophthalmology, Osmania Medical College, Sarojini Devi Eye Hospital. \\ ${ }^{2}$ Senior Resident, Department of Ophthalmology, Osmania Medical College, Sarojini Devi Eye Hospital.
}

ABSTRACT
BACKGROUND
Uveitis is a complex intraocular inflammatory disease that results from several aetiological entities. Anterior uveitis is the most
common form of uveitis and is commonly seen in young adults.
The aim of this study was to evaluate the aetiological and anatomical pattern of anterior uveitis.

\section{MATERIALS AND METHODS}

A prospective clinical study was conducted in Sarojini Devi Eye Hospital, Hyderabad. All patients aged between 20 - 80 years who presented with anterior uveitis were studied. A comprehensive ophthalmic evaluation followed by relevant laboratory investigations was done to determine the aetiology.

\section{RESULTS}

Study population included 69 patients over a period of two years (October 2013 - 15). Anterior uveitis occurred most commonly in the 40 - 50 years' age group (27.53\%). Majority of the cases had non-granulomatous inflammation (79.71\%) and aetiology remained unknown in $66.66 \%$ of the cases. Most common identified cause in the cohort was tuberculosis (20.28\%) followed by rheumatoid arthritis (4.34\%).

\section{CONCLUSION}

In a majority of the cases, the aetiology of anterior uveitis remains undetermined. A tailored battery of investigations based on age, history and clinical findings are needed to facilitate a final diagnosis.

\section{KEYWORDS}

Anterior Uveitis, Aetiology, Non-Granulomatous Inflammation, Tuberculosis, Rheumatoid Arthritis.

HOW TO CITE THIS ARTICLE: Hussain SMP, Mirza A. A prospective study of the clinical profile of patients presenting with anterior uveitis. J. Evolution Med. Dent. Sci. 2016;5(99):7280-7283, DOI: 10.14260/jemds/2016/1647

\section{BACKGROUND}

The term "uveitis" includes a heterogeneous group of diseases, characterised by the presence of ocular inflammation that may damage intraocular structures and result in the loss of vision. Anterior uveitis involves the anterior portion of the uvea (i.e. the iris and ciliary body). "Iritis" refers to an inflammation of the iris only, while "iridocyclitis" involves both the iris and the ciliary body. Along with conjunctivitis, keratitis and acute glaucoma, it is one of the groups of ocular conditions commonly termed "red-eye." This disease is associated with ocular trauma as well as many systemic diseases including rheumatoid arthritis, ankylosing spondylitis, Reiter's syndrome, sarcoidosis, herpes zoster and syphilis.1-5 Common vision-threatening complications of anterior uveitis include cataract, glaucoma and macular oedema. ${ }^{2}$ Because anterior uveitis may be associated with systemic disease and when undetected and untreated can cause loss of vision, the

Financial or Other, Competing Interest: None.

Submission 31-10-2016, Peer Review 29-11-2016,

Acceptance 05-12-2016, Published 12-12-2016.

Corresponding Author:

Dr. Shaik Mohammed Pervaiz Hussain,

H. No. 17-1-462/3, Near Shiva Ganga Theatre,

Beside Green Park Cafe,

Shankeshwar Bazar, Hyderabad-60.

E-mail: zeeshan.drpervaiz786@gmail.com drafiamirza@gmail.com

DOI: $10.14260 /$ jemds/2016/1647

\section{(c) (i) $\$$}

importance of ready access to primary eye care is a public health concern.

The differential diagnosis of anterior uveitis can be accomplished by a thorough eye examination and physical assessment. When properly identified, anterior uveitis is treatable and many of the complications can be avoided. Recognition of the signs and symptoms of systemic causes of anterior uveitis and referral for primary care result in improved patient health.

The acute nature of anterior uveitis in most cases leads the patient to seek care resulting in early detection of the disease. However, chronic forms of anterior uveitis are more insidious and the patient may be asymptomatic. Regular eye examinations provide the opportunity to screen for chronic anterior uveitis. With the early detection and treatment of anterior uveitis, sight threatening complications may be avoided. When a systemic aetiology is suspected, the patient should be referred to their primary care physician or other health care provider for evaluation and treatment.

The literature includes many reports from the Western world describing the epidemiology of uveitis in Caucasians with an annual incidence of 12 - 25 per $1,00,000$ population. 6 A few studies on the pattern of uveitis from Southern ${ }^{7-9}$ Central, North East and Northern India ${ }^{10}$ have been reported in literature. So far there was no report from Hyderabad, Telangana about epidemiology of anterior uveitis. SDEH, Hyderabad being a tertiary care hospital and a major referral centre, a number of cases of anterior uveitis present to the OPD. Hence, in this prospective study, every effort is made to 
establish the cause of uveitis and associated systemic conditions.

\section{MATERIALS AND METHODS}

This prospective study was conducted among the patients reporting to Sarojini Devi Eye Hospital with anterior uveitis during the period of October 2013 to October 2015. The total study population included 69 patients. The diagnosis of anterior uveitis with or without systemic diseases association was based on detailed clinical history, ophthalmological examination, general physical examination, laboratory and ancillary tests.

Ocular examination included external examination, slit lamp biomicroscopy including fundus examination with 90-D or indirect ophthalmoscopy (with scleral depression, when indicated) after full dilatation, applanation tonometry, gonioscopy and ancillary tests including ultrasonography and fundus fluorescein angiography (if required) were conducted. The laboratory investigations were tailored to each case. These tests included complete blood picture, erythrocyte sedimentation rate, complete urine examination, urine culture and sensitivity, stool examination for ova and cysts, random blood sugar, serum uric acid, VDRL, Mantoux skin test. Other investigations included chest x-ray, x-ray sacroiliac joint, HIV, rheumatoid factor, antinuclear antibodies and C-reactive protein.

\section{Inclusion Criteria}

All cases of anterior uveitis presenting to the Outpatient Department of Sarojini Devi Eye Hospital were taken into consideration.

\section{Exclusion Criteria}

- Patients who did not undergo complete investigation profile.

- Patients with intermediate and posterior uveitis.

- Uveitis developing postoperatively.

- Sympathetic ophthalmitis

- Masquerade syndromes.

\section{RESULTS}

\begin{tabular}{|c|c|c|}
\hline Age (Years) & No. of Patients & Percentage (\%) \\
\hline $20-30$ & 7 & 10 \\
\hline $31-40$ & 18 & 26 \\
\hline $41-50$ & 19 & 27.53 \\
\hline $51-60$ & 15 & 21.73 \\
\hline $61-70$ & 08 & 11.59 \\
\hline $71-80$ & 2 & 2.89 \\
\hline Total & $\mathbf{6 9}$ & $\mathbf{1 0 0}$ \\
\hline \multicolumn{3}{|c|}{} \\
\hline Sex & 40 & 57.97 \\
\hline Male & 29 & 42.02 \\
\hline Female & $\mathbf{6 9}$ & $\mathbf{1 0 0}$ \\
\hline Total & Table 1. Age and Sex Distribution of Uveitis \\
\hline
\end{tabular}

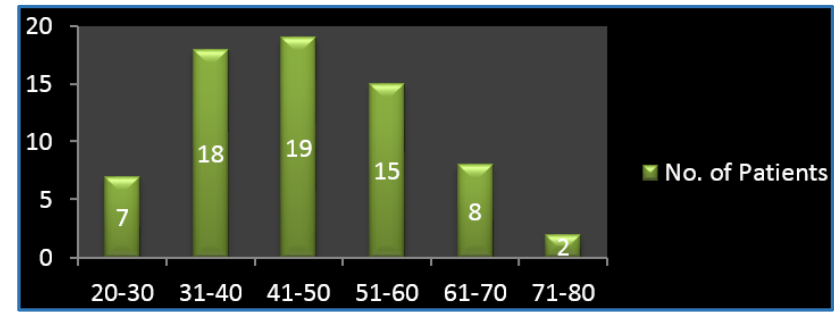

Graph 1. Age Distribution (Years)

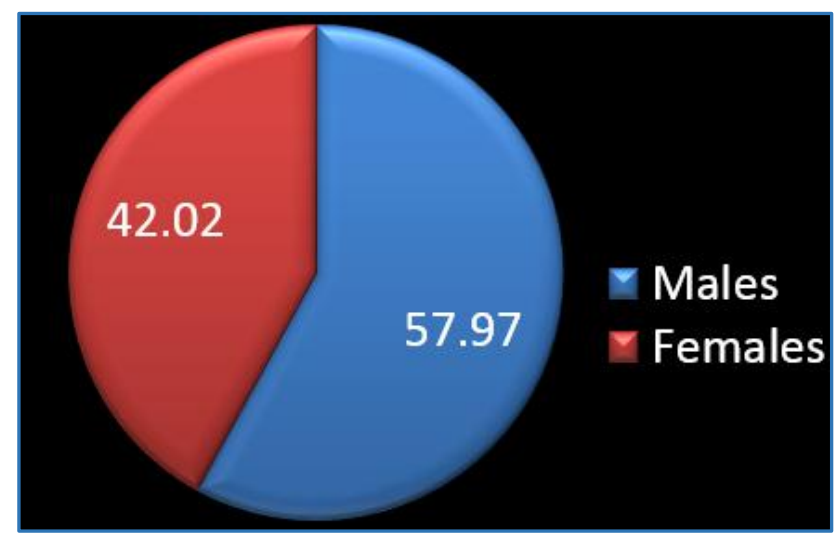

Graph 2. Sex Distribution

\begin{tabular}{|c|c|c|}
\hline Anterior Uveitis & No. of Cases & (\%) \\
\hline Idiopathic & 46 & 66.66 \\
\hline TB & 14 & 20.28 \\
\hline RA & 3 & 4.34 \\
\hline Fuchs & 2 & 2.89 \\
\hline AS & 1 & 1.44 \\
\hline Behcet's & 1 & 1.44 \\
\hline $\begin{array}{c}\text { Phacogenic } \\
\text { Uveitis } \\
\text { Uraumatic } \\
\text { Uveitis }\end{array}$ & 1 & 1.44 \\
\hline Total & $\mathbf{6 9}$ & 1.44 \\
\hline \multicolumn{2}{|c|}{ of Able 2. Aetiological Pattern } \\
\hline
\end{tabular}

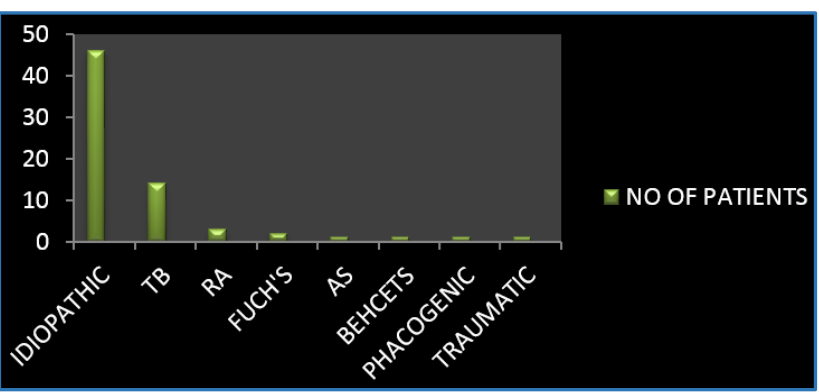

Graph 3. Aetiological Pattern of Anterior Uveitis

\begin{tabular}{|c|c|c|}
\hline Anterior Uveitis & No. of Cases & Percentage (\%) \\
\hline Granulomatous & 14 & 20.28 \\
\hline Non-Granulomatous & 55 & 79.71 \\
\hline Total & 69 & 100 \\
\hline
\end{tabular}




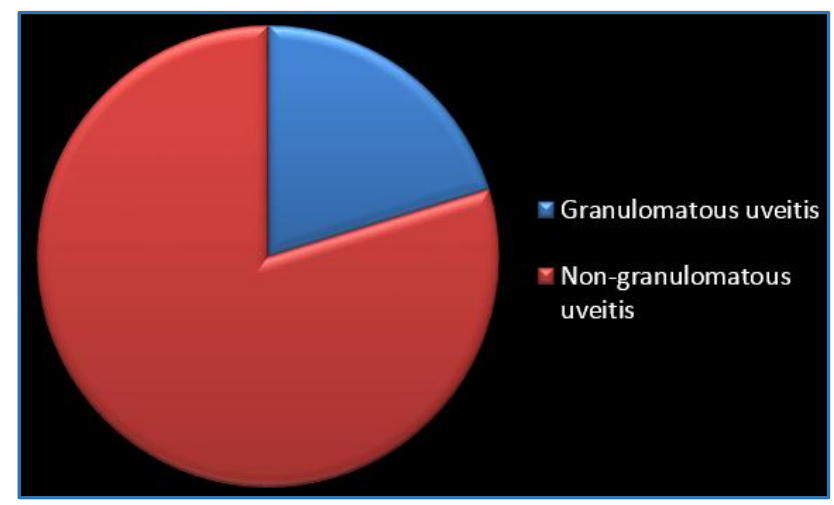

Graph 4. Pathological Patterns of Anterior Uveitis

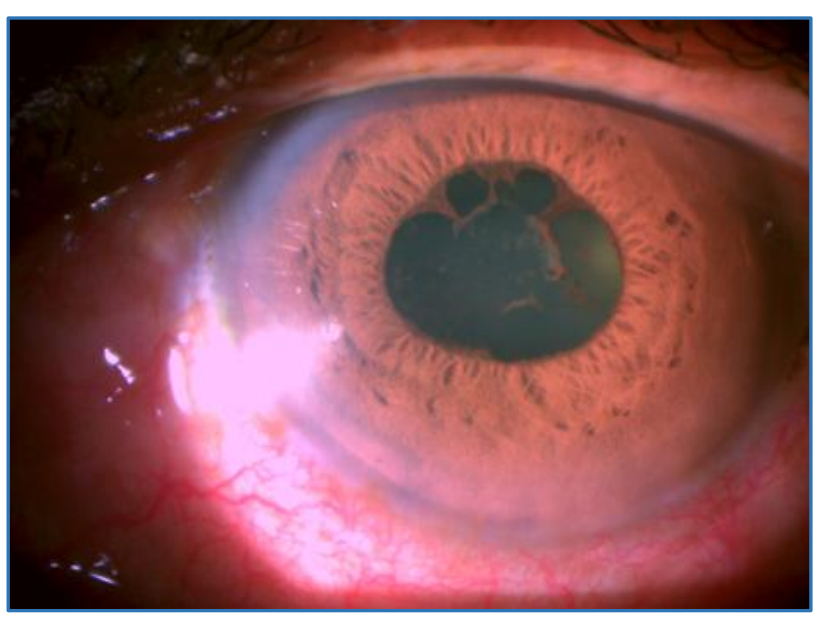

Figure 1. Circumciliary Congestion, Irregular Mid-Dilated Fixed Pupil with Posterior Synechiae from 11 - 1 o'clock and Iris Pigment on Lens in Acute Idiopathic Uveitis

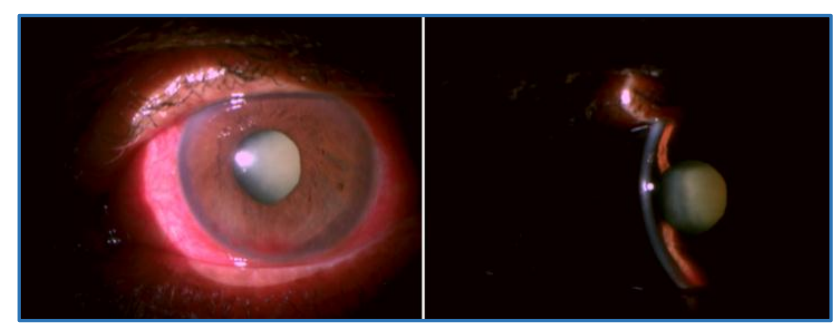

Figure 2. Blood Stained Endothelium, Pigmented Keratic Precipitates, Traumatic Mydriasis and Complicated Cataract in Traumatic Uveitis

\section{DISCUSSION}

To identify the pattern of anterior uveitis in a tertiary care eye centre, a prospective study of all cases of anterior uveitis seen in SDEH was undertaken using a standard protocol and the results were compared with the pattern of uveitis in other parts of India and other countries.

The uveitic population seen in our institute comprised cases from Telangana and Andhra Pradesh. Changing patterns are seen in the studies from the same country done at different periods of time. ${ }^{10}$

\begin{tabular}{|c|c|c|c|}
\hline Studies & Age & \multicolumn{2}{|c|}{ Sex (In \%) } \\
\hline \multirow{2}{*}{ Present Study } & \multirow{2}{*}{38} & Male & Female \\
\cline { 3 - 4 } & & 57.97 & 42.02 \\
\hline Japan Based 11 & 45 & 45 & 55 \\
\hline USA Based 11 & 37 & 52.24 & 49.75 \\
\hline
\end{tabular}

\begin{tabular}{|c|c|c|c|}
\hline Turkey Based ${ }^{11}$ & 36 & 58.2 & 41.8 \\
\hline Dipankar 12 et al & 32 & 67.85 & 32.14 \\
\hline Yellambkar ST 13 et al & $21-30$ & 58.6 & 41.30 \\
\hline Sudha Madhavi ${ }^{14}$ et al & - & 55.75 & 44.25 \\
\hline Biswas $^{8}$ et al & 40 's & 62.21 & 37.79 \\
\hline Singh 15 et al & - & 51.98 & 48.01 \\
\hline
\end{tabular}

In the present study, mean age at presentation was 38 years. Males (40 cases, $57.97 \%$ ) were predominantly affected in the present study in comparison to females (29 cases, 42.02\%). This is similar to various studies from India $8,9,10,15$ and abroad,11,16,17 but in contrary Alezandro Rodriguez et al reported female preponderance of the disease. This may be because men tend to seek medical attention more often than women and socioeconomic habits may put male patients at a greater risk for development of anterior uveitis.

Majority of patients came with unilateral presentation (72.46\%). This finding was comparable with that of Rathinam et al study ${ }^{10}$ (85.3\%). However, there was no significant predilection for either the right or left eye. In this study, specific diagnosis could not be arrived at in $66.66 \%$ of cases. Compared to other studies, incidence of idiopathic uveitis was slightly more because specific investigations like PCR for tuberculosis and HLA-B27 for arthritis cases and treponema pallidum immobilisation test for syphilis could not be done at our centre.

\begin{tabular}{|c|c|}
\hline Studies & Idiopathic Uveitis (\%) \\
\hline Present study & 66.66 \\
\hline Japan based & 42.3 \\
\hline USA based & 34.9 \\
\hline Turkey based & 43.2 \\
\hline Dipankar et al & 45.51 \\
\hline Yellambkar ST et al & 46.6 \\
\hline Sudha Madhavi et al & 42 \\
\hline Biswas et al & 58.6 \\
\hline Singh et al & 24.7 \\
\hline \multicolumn{2}{|c|}{$\begin{array}{l}\text { Table 5. Comparison of Aetiological } \\
\text { Patterns of Anterior Uveitis }\end{array}$} \\
\hline
\end{tabular}

\begin{tabular}{|c|c|}
\hline Studies & Most Common Cause \\
\hline Present study & Tuberculosis \\
\hline Japan based & AS \\
\hline USA based & RA \\
\hline Turkey based & Behcet's Disease \\
\hline Dipankar et al & Seronegative Spondyloarthropathy \\
\hline Yellambkar ST et al & TB \\
\hline Sudha Madhavi et al & Blunt Trauma \\
\hline Biswas et al & -- \\
\hline Singh et al & -- \\
\hline \multicolumn{2}{|c|}{ Table 6. Comparison of Most } \\
Common Cause of Anterior Uveitis \\
\hline
\end{tabular}

\begin{tabular}{|c|c|c|}
\hline Studies & $\begin{array}{c}\text { Granulomatous } \\
\text { (\%) }\end{array}$ & $\begin{array}{c}\text { Non-Granulomatous } \\
\text { (\%) }\end{array}$ \\
\hline Present Study & 20.28 & 79.71 \\
\hline $\begin{array}{c}\text { Sudha Madhavi } \\
\text { et al }{ }^{4} \text { }\end{array}$ & 10 & 90 \\
\hline $\begin{array}{c}\text { Table 7. Comparison of the Pathological Pattern of } \\
\text { Anterior Uveitis with Other Studies (\% of Total } \\
\text { Patients) }\end{array}$ \\
\hline \multicolumn{2}{|c|}{} \\
\hline
\end{tabular}




\section{CONCLUSION}

- In this study, there was higher incidence of uveitis in 41 50 years of age group.

- $\quad$ Males (57.97\%) were commonly affected than females (42.02\%).

- Majority of cases were idiopathic.

- Most common cause was tuberculosis followed by uveitis associated with rheumatoid arthritis.

\section{REFERENCES}

1. Agrawal RV, Murthy S, Sangwan V, et al. Current approach in diagnosis and management of anterior uveitis. Indian J Ophthalmol 2010;58(1):11-9.

2. Schlaegel TF. Essentials of uveitis. Boston: Little, Brown \& Co 1969. New England Journal of Medicine 1970;282(17):982.

3. Rothova A, van Veenendaal WG, Linssen A, et al. Clinical features of acute anterior uveitis. Am J Ophthalmol 1987;103(2):137-45.

4. Rosenbaum JT, Nozik RA. Uveitis: many diseases, one diagnosis. Am J Med 1985;79(5):545-7.

5. Callen JP, Mahl CF. Oculocutaneous manifestations observed in multisystem disorders. Dermatol Clin 1992;10(4):709-16.

6. Islam N. Carlos pavesio, anterior uveitis. BMJ best practice 2015. Available from: http://bestpractice.bmj.com/bestpractice/evidence/background/0705.html.

7. Das D, Biswas J, Ganesh SK. Pattern of uveitis in a referral uveitis clinic in India. Indian J Ophthalmol 1995;43(3):117-21.
8. Biswas J, Narain S, Das D, et al. Pattern of uveitis in a referral uveitis clinic in India. Int Ophthalmol 19961997;20(4):223-8.

9. Dandona L, Dandona R, John RK, et al. Population based assessment of uveitis in an urban population in southern India. Br J Ophthalmol 2000;84(7):706-9.

10. Rathinam SR, Namperumalsamy P. Global variation and pattern changes in epidemiology of uveitis. Indian J Ophthalmol 2007;55(3):173-83.

11. Chams H, Rostami M, Mohammadi SF, et al. Epidemiology and prevalence of uveitis. Iranian Journal of Ophthalmology 2009;21(4):4-16.

12. Das D, Bhattacharjee H, Bhattacharyya PK, et al. Pattern of uveitis in North East India: a tertiary eye care center study. Indian J Ophthalmol 2009;57(2):144-6.

13. Yellambkar ST, Chavan WM, Tayade MC. Clinial study of different types of uveitis in western Maharashtra. Indian Journal of Basic \& Applied Medical Research 2013;7(2):751-5.

14. Madhavi SKM, Kumaraswamy RC. Study of clinical and aetiological pattern of anterior uveitis in middle Karnataka. CHRISMED J Health Res 2015;2(2):124-8.

15. Singh R, Gupta V, Gupta A. Pattern of uveitis in a referral eye clinic in north India. Indian J Ophthalmol 2004;52(2):121-5.

16. Smith RE, Nozik RA. Uveitis: a clinical approach to diagnosis and management. $2^{\text {nd }}$ edn. Baltimore: Williams and Wilkins 1989.

17. Perkins ES, Folk J. Uveitis in London and lowa. Ophthalmologica 1984;189(1-2):36-40. 